\title{
Studies on Characterization of Corn Cob for Application in a Gasification Process for Energy Production
}

\author{
Anthony I. Anukam, ${ }^{1,2}$ Boniswa P. Goso, ${ }^{1}$ \\ Omobola O. Okoh, ${ }^{1}$ and Sampson N. Mamphweli ${ }^{2}$ \\ ${ }^{1}$ Department of Chemistry, University of Fort Hare, Private Bag X1314, Alice 5700, South Africa \\ ${ }^{2}$ Fort Hare Institute of Technology, University of Fort Hare, Private Bag X1314, Alice 5700, South Africa \\ Correspondence should be addressed to Anthony I. Anukam; aanukam@ufh.ac.za
}

Received 7 February 2017; Revised 29 April 2017; Accepted 8 May 2017; Published 11 June 2017

Academic Editor: Kaustubha Mohanty

Copyright (C) 2017 Anthony I. Anukam et al. This is an open access article distributed under the Creative Commons Attribution License, which permits unrestricted use, distribution, and reproduction in any medium, provided the original work is properly cited.

\begin{abstract}
Quintessential characteristics of corn cob were investigated in this study in order to determine its gasification potential. Results were interpreted in relation to gasification with reference to existing data from the literature. The results showed that the gasification of corn cob may experience some challenges related to ash fouling, slagging, and sintering effects that may be orchestrated by high ash content recorded for corn cob, which may contribute to increasing concentration of inorganic elements under high temperature gasification conditions, even though EDX analysis showed reduced concentration of these elements. The study also found that the weight percentages of other properties such as moisture, volatile matter, and fixed carbon contents of corn cob as well as its three major elemental components $(\mathrm{C}, \mathrm{H}$, and $\mathrm{O}$ ) including its clearly exhibited fiber cells make corn cob a suitable feedstock for gasification. FTIR analysis revealed the existence of $-\mathrm{OH}, \mathrm{C}-\mathrm{O}, \mathrm{C}-\mathrm{H}$, and $\mathrm{C}=\mathrm{C}$ as the major functional group of atoms in the structure of corn cob that may facilitate formation of condensable and noncondensable liquid and gaseous products during gasification. TGA results indicated that complete thermal decomposition of corn cob occurs at temperatures close to $1000^{\circ} \mathrm{C}$ at a heating rate of $20^{\circ} \mathrm{C} / \mathrm{min}$.
\end{abstract}

\section{Introduction}

The quest for energy is expanding rapidly all around the world, resulting in increasing pressure on power generating systems in most countries, especially in developing countries such as South Africa. These have necessitated the use of alternative means of power generation that will not only ease the pressure on power generating systems but also have reduced consequential impact on the environment. Renewable source of energy is the most convenient alternative energy source to dwindling power generating capabilities imposed by rising energy demand.

South Africa is one of many developing countries in the world with quite a number of rural settlements that are associated with energy challenges because of the difficulties in extending the national electricity grid to these settlements. Therefore, the energy needs of these remote areas have to be met by off-grid technologies that are economically viable and sustainable. There are basically four different types of off-grid power generation methods, namely, solar, wind, and hydroas well as dendro (biomass)-power generation. Because of the high cost associated with the first three, power generation from biomass happens to be the most convenient and yet efficient method of providing energy to remote settlements; however the importance of the type and availability of the biomass to be used as feedstock in the energy conversion processes cannot be overemphasized [1].

Corn cob (CC) is a biomass feedstock with direct potential as an energy resource that can be used in gasification systems for energy production. It has a number of advantages over other biomass feedstocks including its dense and uniform nature as well as its increased energy content and its low sulfur and nitrogen concentrations [2]. It is an agricultural residue that is generated from maize and remains part of the ear on which the kernels grow. In most established countries, CC is usually disposed and destroyed by fire on the farms 
to prepare for the next coming season. The dumping and burning of $\mathrm{CC}$ on the farms constitute gross air pollution. In South Africa, corn is a very important food for many people and it remains the most critical horticultural harvest for more than 70 million homestead families around the world $[3,4]$.

CC residues are sufficiently available in South Africa and are produced in large quantities by the maize industry, which happens to be one of the largest producers of agricultural residues in the country as approximately 11 million tons of CC is produced per year [5]. The conversion of CC into an energy carrier gas known as syngas through gasification is a viable alternative to electricity generation needed to meet the ever escalating energy demands of remote settlements [6, 7]. Before this can be achieved, there is a need to investigate the characteristics of CC that are relevant to gasification in order to accurately predict its performance during gasification since the operation of energy conversion systems has been quite compromised because of the wide variety of biomass origin that affects its composition and characteristics.

Ethanol production from lignocellulosic biomass is facing quite a number of challenges. Among these issues are getting rid of the lignin content of the biomass (delignification) as well as conversion of its cellulose and hemicellulose contents into fermentable sugars through fermentation [8]. The process of finding a way around these challenges is still under investigation. However, with gasification, any biomass material can be successfully converted into useable energy without the need for delignification. The syngas produced from gasification can be further processed into other chemicals via different reforming processes. It can also be converted into fuels through the Fischer Tropsch process. Another advantage of gasification as compared to other bioenergy generation technologies is its ability to utilize a wide variety of biomass feedstocks ranging from any agricultural or plant residue, industry organic by-products, or even municipal wastes, and hence gasification is considered a viable technique for producing energy from biomass feedstocks, which cannot be technically or economically fermented to ethanol.

Gasification occurs under a sequence of successive reactions that are mostly endothermic in nature. The following reactions take place during biomass gasification $[9,10]$.

Oxidation reaction is

$$
\mathrm{C}+\mathrm{O}_{2} \longrightarrow \mathrm{CO}_{2} \quad(+393 \mathrm{MJ} / \mathrm{kg} \text { mole })
$$

Reduction reaction is

$$
\mathrm{C}+\mathrm{H}_{2} \mathrm{O} \longrightarrow \mathrm{H}_{2}+\mathrm{CO} \quad(+122.6 \mathrm{MJ} / \mathrm{kg} \text { mole })
$$

Water-gas shift reaction is

$$
\mathrm{CO}+\mathrm{H}_{2} \mathrm{O} \longleftrightarrow \mathrm{CO}_{2}+\mathrm{H}_{2} \quad(-41.2 \mathrm{MJ} / \mathrm{kg} \text { mole })
$$

Methanation reaction is

$$
\mathrm{C}+2 \mathrm{H}_{2} \longleftrightarrow \mathrm{CH}_{4} \quad(+75 \mathrm{MJ} / \mathrm{kg} \text { mole })
$$

Reaction (1) typically occurs in the combustion zone of the gasifier with a theoretical temperature of over $1200^{\circ} \mathrm{C}$; hence oxidation reactions of a gasification process are also referred to as combustion zone reactions. The second reaction (reaction (2)) represents the medium where the product of partial oxidation (i.e., products that were not fully combusted in reaction (1)) passes through, which is the reaction representing the red-hot bed of charcoal that is capable of reducing gas temperature because of the reaction's endothermic nature, while reaction (3) depicts the prominent water-gas shift reaction that is the major determinant of the yield and quality of the syngas produced from a gasification process. The fourth reaction (reaction (4)) is the hydrogasification reaction that is also known as the methanation reaction, which forms very minute levels of methane during gasification [9].

Gasifiers operate satisfactorily only within certain ranges of feedstock characteristics, as such knowledge of the characteristics of the feedstock to be used during gasification is required in order to predict its performance prior to gasification [11]. Analytical instruments such as CHNS analyzer, atomic absorption spectrometer (AAS), thermogravimetric analyzer (TGA), and scanning electron microscopic (SEM) analyzer are very useful instruments to determine the characteristics of biomass materials for the purpose of gasification. Previous studies from other researchers have used these instruments to determine the sintering characteristics and mineral transformation behaviour of corn cob ash (CCA) [7]. Kumar et al., 2008 [12], used TGA to study the thermal characteristics of corn stover (CS) as a gasification and pyrolysis feedstock, while Arun and Ramanan, 2016 [13], conducted experimental studies on the gasification of CC in a fixed-bed system after determining the characteristics of $\mathrm{CC}$ using a muffle furnace, an ultimate analyzer, and a bomb calorimeter to provide information on physical and chemical properties of the material as well as its energy content, respectively. In another study, Aboyade et al., 2013 [14], determined the nonisothermal thermokinetics of copyrolysis of a blend of two different biomass materials that included corn residue with coal. In addition to the physical, chemical, and thermal properties of CC, there is a lack of specific information on its characterization intended to reveal its surface and internal structural properties for the purpose of gasification. The objective of this study, therefore, is to establish the characteristics of CC relevant to gasification in a downdraft system and to interpret the information obtained from these characteristics in relation to gasification based on existing data from the literature.

The characteristics of CC in terms of proximate and ultimate analysis as well as in terms of energy value (heating value) reported by previous researchers for various applications different from gasification are presented in Tables 1 and 2 , respectively.

The difference in the reported values in both Tables 1 and 2 may be essentially due to a combination of factors that includes the source of the CC, its handling, storage, and climatic conditions as well as soil type and texture where the corn was grown including the tendency of the corn plant to uptake nutrients from the soil. The ash content varied probably because of different methods of harvesting and the amount of nutrients (fertilizers) applied to the corn plant during growth. It is valuable from another overview that 
TABle 1: Proximate analysis of corn cob from previous studies (wt.\%).

\begin{tabular}{lcccc}
\hline Author & MC & VM & AC & FC \\
\hline$[15]$ & 4.6 & 79.9 & 1.8 & 13.7 \\
{$[16]$} & 11.74 & 72.33 & 10.67 & 4.97 \\
{$[17]$} & - & 78.7 & 0.9 & 16.2 \\
\hline
\end{tabular}

TABLE 2: Ultimate analysis of corn cob from previous studies (wt.\%).

\begin{tabular}{lcccccc}
\hline Author & $\mathrm{C}$ & $\mathrm{H}$ & $\mathrm{N}$ & $\mathrm{S}$ & $\mathrm{O}$ & $\mathrm{HHV}(\mathrm{MJ} / \mathrm{kg})$ \\
\hline$[15]$ & 50.2 & 5.9 & 0.42 & 0.03 & 43.5 & 19.14 \\
{$[16]$} & 46.2 & 5.42 & 0.92 & 0.24 & 47.22 & 18.36 \\
{$[17]$} & 45.5 & 6.2 & 1.3 & - & 47.0 & - \\
\hline
\end{tabular}

the inorganic compounds contained in CC with higher ash content have potential to be used as catalyst in thermal conversion systems [16].

\section{Experimental}

2.1. Sample Preparation. The corn cob (CC) used for this study was obtained from a local farm in Alice, in the Eastern Cape Province of South Africa. It was dried outdoors at an average temperature of about $30^{\circ} \mathrm{C}$ to lower its moisture content. This was followed by milling to a size required by the instruments that were used for analyses. The dried and milled CC was preserved in a desiccator prior to analyses.

2.2. Proximate Analysis. Information required for moisture, volatile matter, and ash as well as fixed carbon contents of CC was given by proximate analysis. These properties are relevant to the thermal conversion of any biomass material into energy [19]. The proximate analysis data of CC was obtained from the TGA plot presented in Figure 2 following a modified ASTM D 5142-04 standard test method $[18,20]$. They were obtained according to the equations in Table 3.

Moisture content was determined by weight loss at temperatures close to $100^{\circ} \mathrm{C}$, while volatile matter content represented the mass evolved between the temperatures of 100 and $550^{\circ} \mathrm{C}$. After heating of the sample to about $1000^{\circ} \mathrm{C}$ during TGA, the remaining mass was considered as being ash and the fixed carbon content of CC was obtained by difference.

2.3. Ultimate Analysis. This analysis provided information on the elemental components of CC both in qualitative and in quantitative terms. A Thermo Quest CHNS elemental analyzer was used for this purpose. The proportion of carbon (C), hydrogen $(\mathrm{H})$, sulfur $(\mathrm{S})$, and nitrogen $(\mathrm{N})$ were determined, while oxygen $(\mathrm{O})$ was obtained by difference.

About $5 \mathrm{mg}$ of milled CC was placed in a tin capsule that contained an oxidizer prior to combustion in a reaction at $1000^{\circ} \mathrm{C}$. This led to a violent reaction as the sample and tin capsule decomposed, creating a condition where all heat resistant substances became fully oxidized. The products obtained were made to pass through a high purity copper at
TABLE 3: Equation parameters used for proximate analysis determination from TGA curve [18].

\begin{tabular}{lc}
\hline $\begin{array}{l}\text { Equation } \\
\text { name }\end{array}$ & Parameters \\
$\begin{array}{l}\text { Moisture } \\
\text { content }\end{array}$ & $\left(\frac{([\text { Initial Mass }]-[\text { Moisture Mass }])}{[\text { Initial Mass }]}\right) \times 100$ \\
$\begin{array}{l}\text { Volatile } \\
\text { matter } \\
\text { content }\end{array}$ & $\left(\frac{([\text { Moisture Mass }]-[\text { Volatile Mass }])}{[\text { Initial Mass }]}\right) \times 100$ \\
$\begin{array}{l}\text { Ash } \\
\text { Fixed } \\
\text { carbon }\end{array}$ & $100-([$ Moistial Mass $]$ \\
\hline
\end{tabular}

$500^{\circ} \mathrm{C}$ in order to rid the process of any oxygen that was not completely consumed during the combustion process. There is always a need to employ high purity substances during CHNS analyses for the purpose of oxidation and to remove unwanted materials that may interfere with analyses results [21]. Complete oxidation was ensured by using tungsten trioxide and copper downstream of the combustion chamber of the instrument. Combustion products such as carbon dioxide $\left(\mathrm{CO}_{2}\right)$, sulfur dioxide $\left(\mathrm{SO}_{2}\right)$, and nitrogen dioxide $\left(\mathrm{NO}_{2}\right)$ were obtained after the analysis, which were all separated by gas chromatography and the elements measured with a thermal conductivity detector.

The energy value, also known as heating value and reported in terms of higher heating value (HHV) of CC, was calculated from the mass fractions of the elemental components obtained from CHNS analysis, which was done according to [22]

$$
\begin{aligned}
\mathrm{HV}(\mathrm{MJ} / \mathrm{kg})= & -1.3675+0.3137 \times \mathrm{C}+0.7009 \times \mathrm{H} \\
& +0.0318 \times \mathrm{O},
\end{aligned}
$$

where $\mathrm{HV}$ is the heating value measured in $\mathrm{MJ} / \mathrm{Kg}$, while $\mathrm{C}$, $\mathrm{H}$, and $\mathrm{O}$ are the carbon, hydrogen, and oxygen contents of CC.

2.4. FTIR Analysis. The Fourier Transform Infrared (FTIR) spectroscopy also deals with quantitative and qualitative analysis of organic samples and recognizes chemical bonds in a molecule by generating an infrared retention range; the spectra generate a profile of the sample, a particular molecular fingerprint that can be utilized to screen and scan samples for a wide range of segments [23]. FTIR is an operative analytical instrument for distinguishing functional groups and characterizing covalent bonding data. In this study, it was used to determine the most reactive components of CC in terms of functional groups since the rate of gasification reactions depend on the chemically active group of components of the biomass used as feedstock [24].

About $0.5 \mathrm{mg}$ of the sample was mixed with $0.25-0.50$ of $\mathrm{KBr}$ and placed in the FTIR test holder. The sample 
was examined by a fully computerized Perkin Elmer FTIR system which produces the absorbance spectra that demonstrate the unique chemical bonds and the atomic structure of the sample material. This profile was in the form of an absorption spectrum that indicated peaks representing components in higher concentration. Absorbance peaks on the spectrum also indicated the functional groups. Different types of bonds and thus different functional groups absorbed infrared radiation of various wavelengths. Despite the fact that the analysis was performed in absorbance mode, it can be converted into a transmittance mode since they are just the reverse of each other. The analytical spectrum is then contrasted in a reference library program with cataloged spectra to identify components for unknown material using the cataloged spectra for known materials.

2.5. Thermogravimetric Analysis (TGA). The thermal behaviour of biomass materials are usually measured by a thermogravimetric analyzer (TGA), which measures the percentage weight loss of the biomass as a function of temperature and the resulting thermogram has a peculiar shape for biomass materials [25]. In addition to studying the thermal behaviour of CC, this analysis was undertaken in order to establish the thermal parameters that would impact on the gasification of the material. It is worth noting that most TGA experiments are conducted under a chemically inactive environment (of which nitrogen or argon is often used) to show the effect of heat degradation that includes carbonization; oxygen is highly reactive and usually not recommended during analyses involving TGA because it reacts with sample components, leading to loss of original sample in the process [24].

A $7.81 \mathrm{mg}$ of the sample was combusted in a SDT Q600 TGA instrument under a nitrogen atmosphere at a flow rate of $35 \mathrm{~mL} / \mathrm{min}$ between 35 and $1000^{\circ} \mathrm{C}$. Nitrogen was used to create a chemically inactive environment so as to prevent the TGA instrument from overheating. A heating rate of $20^{\circ} \mathrm{C} / \mathrm{min}$ was used during TGA because this is characteristic of gasification systems using the downdraft gasifier [11].

2.6. SEM Analysis. Scanning Electron Microscopy (SEM) is a high resolution imaging system with an extraordinary depth of field. It indicates topographical, structural, and elemental data at low magnifications up to 200,000x [26]. The utilization of SEM innovation is a priceless guide in distinguishing and portraying mineral and material stages together with surface components. SEM in this study was used for surface morphological view of the material to establish if CC is enough carbonaceous material that would be suitable for gasification using the downdraft gasification system.

The SEM analysis of CC was undertaken by a JEOL (JSM-6390) operating with accelerating voltage of $15 \mathrm{kV}$. The micrographs were generated at different magnifications (250-1000x) by a computer program. The data was collected over a selected area of the surface of the sample and a two-dimensional image was generated that displayed spatial variations in properties.
TABLE 4: Measured physical characteristics of corn cob.

\begin{tabular}{lc}
\hline Proximate analysis (wt.\%) & \\
\hline Moisture content & 5.1 \\
Volatile matter content & 65.1 \\
Ash content & 8.5 \\
Fixed carbon & 21.3 \\
\hline
\end{tabular}

\section{Results and Discussion}

In this section, the findings of this study are presented, discussed, and substantiated with reference to existing data from the literature.

3.1. Physical Characteristics of Corn Cob. Gasifiers, among other factors, operate satisfactorily with regard to efficiency only within certain ranges of feedstock characteristics [11]. Table 4 shows the data obtained from the physical characterization of CC, which were obtained from the thermogravimetric plot of the sample presented in Figure 2, employing the equations presented in Table 3.

From Table 4, moisture content of CC was measured as $5.1 \%$, which is quite different when compared to the values reported in the literature. It is lower than the value of $11.74 \%$ reported by Danish et al., 2015 [16], and higher than the value of $4.6 \%$ reported by Danje, 2011 [15], in Table 1. The difference in these values may be attributed to a number of reasons including the source of the CC and handling conditions. However, this value (5.1\%) for moisture content is desirable for gasification to take place as materials with moisture content beyond $20 \%$ would create technical difficulties linked to poor combustion conditions within the gasification system and will inhibit immediate combustion of the material at the same time increasing its smoking propensity with a consequent reduction in gasification process efficiency [24]. It can also be noted that the CC used for this study is characterized by relatively high volatile matter content (65.1\%), which was anticipated because of the organic nature of the material. The contents of volatile matter in biomass materials are usually high due to the organic nature of the biomass, which indicates the biomass potential to create huge amounts of inorganic vapours when used as feedstock in a gasification process; the higher the volatile matter content of biomass, the better its combustion and gasification rates because of the biomass yield upon carbonization [25]. The material is also characterized by high ash content that may also be attributed to a number of factors that include those previously given in Section 1. This high content of ash may not be favourable to gasification because of issues linked to sintering and slagging that may be experienced during gasification, which might also contribute to reduction in process efficiency. Biomass ash content greater than $6 \%$ is not desirable for gasification because it creates technical issues related to agglomeration, fouling, and sintering as well as slagging that may together reduce gasification efficiency; however, ash may exert some catalytic effect that may allow for cracking of higher molecular weight compounds such as 
TABLE 5: Measured elemental components of corn cob.

\begin{tabular}{lc}
\hline Ultimate analysis (wt.\%) & \\
\hline $\mathrm{C}$ & 44.4 \\
$\mathrm{H}$ & 5.6 \\
$\mathrm{~N}$ & 0.43 \\
$\mathrm{~S}$ & 1.3 \\
O (by difference) & 48.27 \\
\hline
\end{tabular}

tar into lighter ones for optimum gasification efficiency [2729]. The fixed carbon content of CC was also found to be about $21 \%$, which is high enough to allude that there will be increased formation of char during gasification as the relative proportions of the content of volatile matter and fixed carbon are related to the yields and composition of solid, liquid, and gaseous products formed during gasification [30].

3.2. Chemical Characteristics of Corn Cob. The ratio of the products formed during gasification of biomass is influenced not just by its physical characteristics but also by the chemical composition of the biomass fuel and the operating conditions of the gasifier [31]. The chemical properties of CC was studied in order to obtain information regarding the relative proportions of the major elemental components of the material and to predict the impact of these components on syngas quality and yield as well as on the environmental effects of gasifying CC. Table 5 shows the elemental components of CC as measured by the CHNS analyzer.

The data in Table 5 shows that CC is composed of three major elements with a higher proportion of oxygen than carbon. The higher oxygen proportion is the reason for the low energy value reported for CC in Section 3.5. However, this higher oxygen content implies increased thermal reactivity during gasification. Increased biomass oxygen content is an indication of increased thermal reactivity of biomass during thermochemical conversion processes; the gasification of biomass is centered on carbon conversion [11]. The content of hydrogen is in agreement with most findings in the literature and had positive contribution to the energy value of CC reported in Section 3.5 together with its content of carbon. Oxidation of carbon and hydrogen contents of biomass are usually initiated by exothermic reactions during gasification, forming $\mathrm{CO}_{2}$ and $\mathrm{H}_{2} \mathrm{O}$, with the $\mathrm{CO}_{2}$ emitted as a product of complete combustion [24]. The relatively low nitrogen and sulfur contents imply lower amounts of $\mathrm{NH}_{3}, \mathrm{HCN}$, and $\mathrm{H}_{2} \mathrm{~S}$ (which are environmentally harmful compounds) may be anticipated during gasification.

3.3. Metallic Elemental Components of Corn Cob. In addition to nonmetallic elemental components of biomass, there are also metallic elemental components such as $\mathrm{Na}, \mathrm{K}, \mathrm{Mg}$, and $\mathrm{Si}$ that are especially responsible for the concentration of ash in biomass materials; in other words, the weight percentage of these metallic elements, to an extent, determines the overall weight percentage of ash contained in biomass as high concentration of these elements creates technical hitches such as fouling, sintering, and slagging because of volatilization of
TABLE 6: Weight percentages of the metallic elemental components of corn cob.

\begin{tabular}{lc}
\hline Element & Composition (wt.\%) \\
\hline $\mathrm{Al}$ & 0.31 \\
$\mathrm{~K}$ & 1.53 \\
$\mathrm{Si}$ & 0.44 \\
$\mathrm{Na}$ & 1.32 \\
$\mathrm{Ca}$ & 0.11 \\
$\mathrm{Mg}$ & 0.42 \\
$\mathrm{Fe}$ & 0.06 \\
\hline
\end{tabular}

the elements, which forms liquid slags on cooling when the biomass is used as feedstock in gasification processes [32]. Table 6 shows the weight percentages of the metallic elements contained in CC, which were obtained after analysis using a Thermo Scientific Model ICE 3500 Atomic Absorption Spectrometer (AAS) equipped with hollow cathode lamps.

It is quite obvious that the concentrations of the metallic elements are relatively low, implying that there may be little or no technical issues related to those previously mentioned when CC is used as feedstock in a gasification process. The reasons for the low concentration of these elements are the same as those given for the high content of ash reported in Table 4 . These ash-forming elements are usually taken up by plants during growth; the elemental composition of biomass, especially with regard to the weight percentages of the ashforming elements, has key impact on ash transformation sequences and sintering behaviours [7, 24]. Ash-forming elements are usually characterized by complex transformation reactions during biomass gasification, creating technical issues linked to those previously mentioned; however, reactions involving the oxides of calcium or magnesium with potassium silicates lead to formation of high-temperaturemelting calcium-magnesium-potassium silicates that play significant roles in the reduction of sintering issues during gasification because of the limit in the formation of silicates that are rich in potassium [7, 24, 33, 34]. For fixed-bed gasification systems such as the downdraft system, ashrelated sintering proceeds with the formation of slag as a consequence of certain factors like bridging, coalescence, and accumulation of the sintered ash residues on gasifier grates. The slag with large sizes cannot be transported out from the grate, which then interferes with the gasification process and reduces the performance of gasification appliances [35-37].

3.4. Reactive Components of Corn Cob. To gain a deeper understanding of the chemistry of CC and to provide a baseline for the prediction of its gasification performance, a diagnosis of the internal structure of the material is necessary. This diagnosis relates to analysis of the material's reactive components in terms of the functional groups present in its structure. The spectrum associated with the structure of CC and the indicated peaks relative to each functional group are presented in Figure 1. The absorbance at various wavenumbers corresponds to the functional groups. 


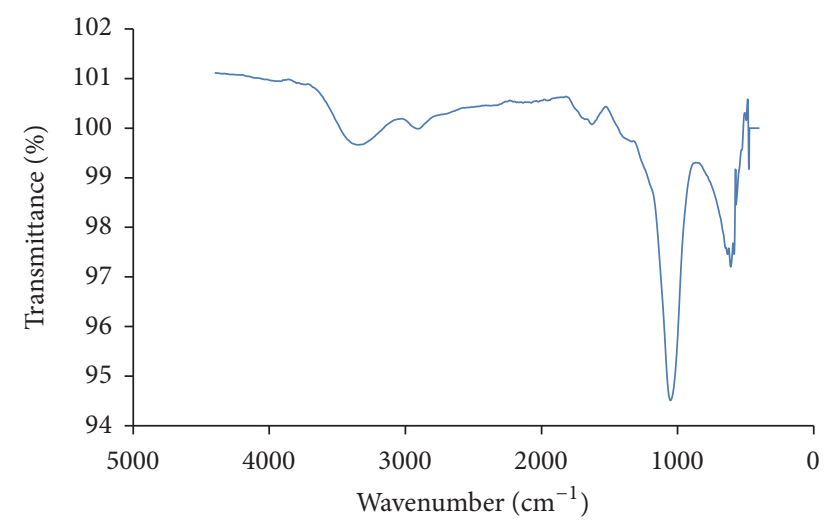

FIgURE 1: FTIR spectrum of corn cob.

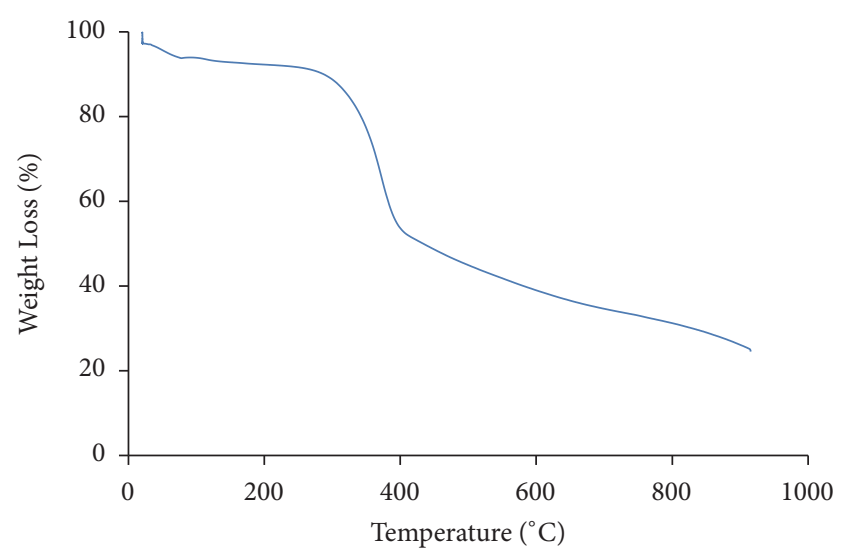

FIGURE 2: Thermogram resulting from the thermal analysis of corn cob.

It is quite obvious from Figure 1 that the peak at $3303 \mathrm{~cm}^{-1}$ corresponds to $\mathrm{O}-\mathrm{H}$ stretching vibrations that indicates the presence of hydroxyl groups, while that near $2844 \mathrm{~cm}^{-1}$ depicts $\mathrm{C}-\mathrm{H}$ stretching that corresponds to the presence of alkanes. $1000 \mathrm{~cm}^{-1}$ depicts $\mathrm{C}-\mathrm{O}$ stretching, with the peak near $600 \mathrm{~cm}^{-1}$ showing characteristics of $\mathrm{C}-\mathrm{H}$ bending. These functional groups represent the chemically active components of biomass that accelerates the rates of the gasification reactions presented in Section 1 [24].

Nonetheless, for better understanding of the functional groups common to the structure of CC, Table 7 presents the chemically active components related to the bonds of the atoms that make up the material and which take part during thermal conversion processes.

During gasification, the presence of the $-\mathrm{OH}$ group will initiate and accelerate the rate of condensation reactions created by dehydroxylation as a result of thermal decomposition of the cellulose content of the material caused by rising temperatures within the gasifier, while $\mathrm{C}-\mathrm{H}$ presence due to alkanes is connected to the reactions leading to hemicellulose degradation [24]. The existence of the $\mathrm{C}=\mathrm{C}$ group, which is an indication of the presence of alkenes, facilitates reactions leading to lignin decomposition; while the group $\mathrm{C}-\mathrm{O}$, which is assigned to carboxylic groups in
TABLE 7: Functional groups present in the structure of corn cob.

\begin{tabular}{lcc}
\hline $\begin{array}{l}\text { Frequency } \\
\text { range } \\
\left(\mathrm{cm}^{-1}\right)\end{array}$ & Groups & Class of compounds \\
\hline 3303 & O-H stretching & Alcohol, phenols \\
2844 & C-H stretching & Alkanes \\
1589 & C=C bending & Aromatic compounds \\
1029 & C-O stretching & Alcohol, phenols \& esters \\
582 & C-H bending & Aromatic compounds \\
\hline
\end{tabular}

cellulose and hemicellulose, speeds up the rate of other reactions such as decarboxylation reactions that leads to the breakage of glycosidic bonds that consequently forms a series of less oxygen-containing compounds such as ethers, acids, and aldehydes and noncondensable gases such as $\mathrm{CO}$ and $\mathrm{CO}_{2}[24,38]$.

Plant photosynthesis is usually driven by energy from the sun that is usually stored in chemical bonds of the structural components of the plant, implying that an amount of energy would be required to break these bonds in order to harness the energy, which is mostly achieved through initiation of gasification reactions when the plant material is to be used as feedstock in a gasification process $[11,28]$.

3.5. Energy Value of Corn Cob. Plants convert energy from the sun into chemical energy that is stored in the structural components of the biomass by using $\mathrm{CO}_{2}$ in the atmosphere [24]. The energy value of $\mathrm{CC}$ was determined to evaluate the amount of energy available for conversion, which is a very important property of biomass because conversion efficiency of a gasification process depends on it [11]. In this study, the energy value of CC was measured as $18.02 \mathrm{MJ} / \mathrm{kg}$, a value that is in agreement with those reported by Danje, 2011 and Danish et al., 2015 [15, 16], in Table 2. It is therefore sufficient to allude that the energy value of CC measured in this study is in agreement with most findings in the literature.

3.6. Thermal Behaviour of Corn Cob. In order to better understand the gasification characteristics of CC, thermal analysis of the sample using an instrument relevant to gasification is necessary. This analysis is intended to establish the thermal behaviour of the sample under both high and low temperatures as well as determine the thermal parameters that would influence its gasification. Figure 2 shows the thermogram obtained from the thermogravimetric analysis of CC.

The plot in Figure 2 shows that as temperature increases there is a marked reduction in the weight of the sample. The plot also shows that the thermal degradation behaviour of CC is characterized by three different weight loss stages with the initial one at $94^{\circ} \mathrm{C}$, which signifies the removal of moisture from the sample. A significant weight loss could be observed between 200 and $500^{\circ} \mathrm{C}$ and represents the second stage of the decomposition process of the sample. This may be attributed to the decomposition of basic organic components of CC such as cellulose, hemicellulose, and lignin; the decomposition of 


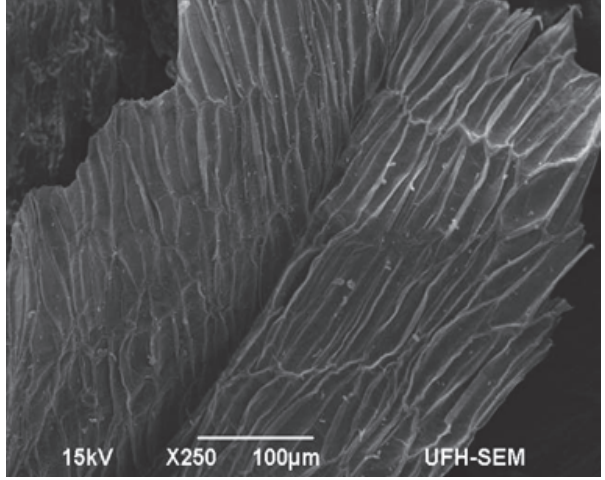

(a)

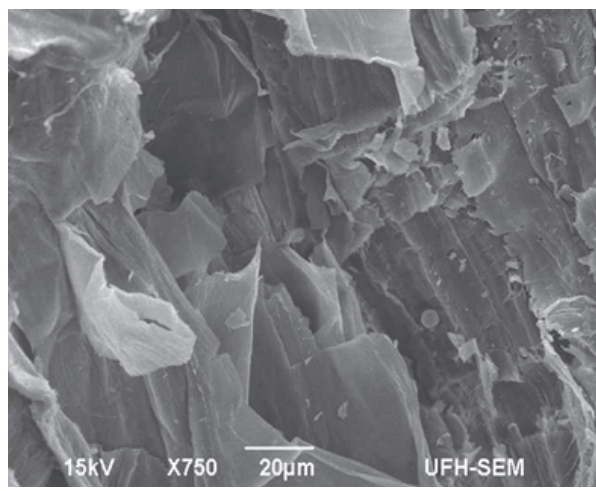

(c)

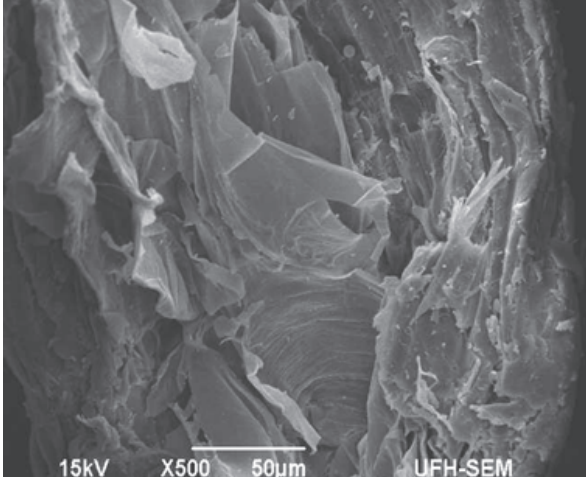

(b)

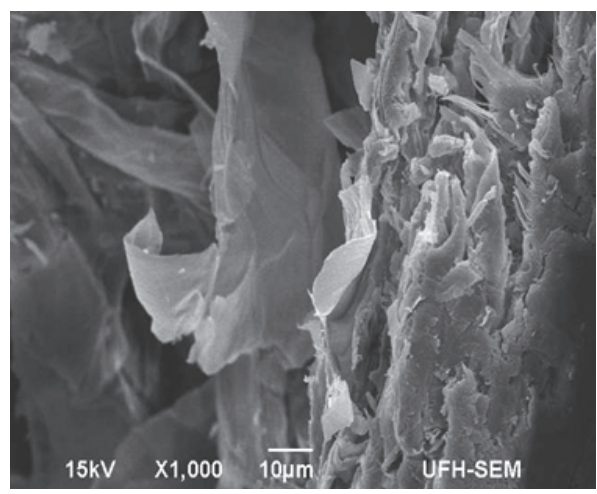

(d)

FIgURE 3: SEM images of corn cob obtained at different magnifications.

these components releases volatile gases such as $\mathrm{CO}_{2}$ and $\mathrm{CH}_{4}$ that are mainly formed due to the decomposition of hemicellulose between the temperatures of 190 and $320^{\circ} \mathrm{C}$. This degradation temperature for hemicellulose implies less production of tar and char during gasification of CC [24]. The third stage of the thermal decomposition process of $\mathrm{CC}$ is indicated by cellulose and lignin degradation between 280 and $400^{\circ} \mathrm{C}$ for cellulose and between 320 and $450^{\circ} \mathrm{C}$ for lignin, with total combustion of the sample taking place as its weight is reduced in the process to give rise to decomposition of hydrocarbons. During gasification, cellulose and lignin degradation at higher temperatures depict the production of carbonized biomass as well as heavy organic and inorganic compounds $[39,40]$.

3.7. Microstructural Characteristics of Corn Cob. The surface structure of CC was examined with a scanning electron microscopic instrument that offered detailed information on imaging and surface composition of the sample. This provided a guide as to whether CC is enough carbonaceous material suitable for gasification in a downdraft gasifier. Figure 3 shows the SEM images of CC obtained at different magnifications. The images were magnified by a factor of 250 for better understanding and interpretation of the microstructural characteristics of the material.

As can be seen from the images in Figures 3(a)-3(d), the shapes are quite irregular and agglomerated. The sample is clearly seen to have no pores even at higher magnifications, an evidence of lack of pretreatment prior to analysis but it exhibits cells on the surface without much characterized structure. However, at 250 magnification (Figure 3(a)) there seem to be plenty of parallel lines that appear on the surface of the sample, which look like cells of residual pith that provides a pathway for the transportation of water and nutrients from the soil, but on increasing magnification to 500 (Figure 3(b)) these lines seem to disappear, showing more vascular bundles with not too conspicuous fragmented cells which indicates fibrous lignocellulosic nature of CC, which is a common feature of agricultural biomass residues [24]. At higher magnification $(\times 750$, Figure $3(c))$, the vascular bundles are more pronounced with the fragmented cell structures more visible. The presence of the vascular bundles and cell structures are an indication of carbon-oriented structures which corroborates the carbon content data of CC presented in Table 5. These cell structures are also associated with the formation of pathways for the production of gaseous products; these features make CC amenable to high temperature gasification that connotes optimum efficiency [24, 39, 41]. As image magnification was increased to a maximum of 1000 (Figure 3(d)), more features were revealed including the size of the vascular bundles and their compact nature, which are important features used to understand the combustion behaviour of biomass materials [42]. 


\section{Conclusions}

In order to evaluate $\mathrm{CC}$ with regard to its gasification-related characteristics, a detailed assessment based on fuel analysis was performed. The experiments conducted and the results presented showed that CC is a biomass feedstock suitable for gasification due to its low moisture content and due to its low concentration of metallic elements. However, its high percentage of ash may create a bit of technical challenges that may lower gasification efficiency. Its low concentration of nitrogen and sulfur implies reduced emissions of $\mathrm{NO}_{X}$ and $\mathrm{SO}_{2}$ during gasification; and its hydrogen concentration is high enough to initiate the water-gas shift reaction that is the dominant chemical reaction which forms the major portion of the syngas. The energy value analysis showed that CC contains a manageable amount of energy that can be converted into useful energy through gasification. The reactive components of CC were mostly oxygen-containing functional groups that may play important roles during gasification. The study also established that the thermal decomposition of CC began at temperatures below $100^{\circ} \mathrm{C}$, with its complete degradation occurring at temperatures close to $1000^{\circ} \mathrm{C}$, releasing enormous amount of gases, while SEM analysis revealed compacted vascular bundles and fiber tissues linked to carbon-orientation that are among the features of CC that may favour high temperature gasification.

The results obtained form a significant basis for the development of a gasification system that would be tailored to the demands of the characteristics of CC.

Even though the CC used for this study exhibited low concentration of metallic elements, an elevated weight percentage of these elements is anticipated when the material is used as feedstock in a gasification process. This is because of the high amount of ash recorded for CC. The weight percentage of the metallic elements of biomass increases with rising gasification temperature [24]. As such, further research is required on reduction of the weight percentage of CC ash content. This study did not involve the gasification of CC either via simulation or via experimental investigation of its gasification process. This is where challenges could be experienced with the use of CC. It is therefore recommended that research be undertaken on the gasification of CC in order to adequately establish the impact of fuel characteristics on gasification process efficiency. The reaction kinetics of the thermal decomposition of CC also require further studies.

\section{Conflicts of Interest}

The authors declare that they have no conflicts of interest.

\section{Acknowledgments}

The authors wish to acknowledge the financial support of the National Research Foundation of South Africa (NRF), the Govan Mbeki Research and Development Center (GMRDC), and the Chemistry Department of both the University of Fort Hare and the Fort Hare Institute of Technology (FHIT), for their technical assistance.

\section{References}

[1] D. Gunarathne, Optimization of the performance of downdraft biomass gasifier installed at national engineering research and development (NERD) Centre of Sri Lanka [Msc thesis], KTH School of Industrial Engineering and Management, Sweden, 2012.

[2] Extension Farm Energy, "Corn cobs for biofuel production," http://articles.extension.org/pages/26619/corn-cobs-for-biofuelproduction, 2016.

[3] J. T. Oladeji and C. C. Enweremadu, "A predictive model for the determination of some densification characteristics of corncob briquettes," in Materials and Processes for Energy: Communicating Current Research and Technological Developments, pp. 169$177,2013$.

[4] Y. Zhang, A. E. Ghaly, and B. Li, "Physical properties of corn residues," American Journal of Biochemistry and Biotechnology, vol. 8, no. 2, pp. 44-53, 2012.

[5] SA Department of Agriculture, "Maize production," http://nda .agric.za/publications, 2016.

[6] M. Y. Suberu, A. S. Mokhtar, and N. Bashir, "Potential capability of corn cob residue for small power generation in rural Nigeria," ARPN Journal of Engineering and Applied Sciences, vol. 7, no. 8, pp. 1037-1046, 2012.

[7] L. Wang, J. E. Hustad, and M. Grønli, "Sintering characteristics and mineral transformation behaviors of corn cob ashes," Energy and Fuels, vol. 26, no. 9, pp. 5905-5916, 2012.

[8] J. Lee, "Biological conversion of lignocellulosic biomass to ethanol," Journal of Biotechnology, vol. 56, no. 1, pp. 1-24, 1997.

[9] R. N. André, F. Pinto, C. Franco et al., "Fluidised bed cogasification of coal and olive oil industry wastes," Fuel, vol. 84, no. 12-13, pp. 1635-1644, 2005.

[10] J. Fermoso, Pressure co-gasification of coal and biomass for the production of hydrogen, University of Oviedo, Spain, 2009.

[11] A. Anukam, S. Mamphweli, E. Meyer, and O. Okoh, "Computer simulation of the mass and energy balance during gasification of sugarcane bagasse," Journal of Energy, vol. 2014, Article ID 713054, 9 pages, 2014.

[12] A. Kumar, L. Wang, Y. A. Dzenis, D. D. Jones, and M. A. Hanna, "Thermogravimetric characterization of corn stover as gasification and pyrolysis feedstock," Biomass and Bioenergy, vol. 32, no. 5, pp. 460-467, 2008.

[13] K. Arun and M. V. Ramanan, "Experimental studies on gasification of corn cob in a fixed bed system," Journal of Chemical and Pharmaceutical Research, vol. 8, pp. 667-676, 2016.

[14] A. O. Aboyade, J. F. Görgens, M. Carrier, E. L. Meyer, and J. H. Knoetze, "Thermogravimetric study of the pyrolysis characteristics and kinetics of coal blends with corn and sugarcane residues," Fuel Processing Technology, vol. 106, pp. 310-320, 2013.

[15] S. Danje, Fast pyrolysis of corn residues for energy production [dissertation, thesis], Stellenbosch University, 2011.

[16] M. Danish, M. Naqvi, U. Farooq, and S. Naqvi, "Characterization of South Asian agricultural residues for potential utilisation in future energy mix," Energy Procedia, vol. 75, pp. 2974-2980, 2015.

[17] J. Wannapeera, N. Worasuwannarak, and S. Pipatmanomoi, "Product yields and characteristics of rice husk, rice straw and corncob during fast pyrolysis in a drop-tube/fixed-bed reactor," Songklanakarin Journal of Science and Technology, vol. 30, no. 3, pp. 393-404, 2008. 
[18] Leco Corporation, Moisture, Volatile Matter, Ash, and Fixed Carbon Determination-Solid Fuel Characterization Measurements in Coke, Organic Application Note, Form 203-821-381, LECO Corporation, St. Joseph, Mich, USA, 2010, http://www.leco.co .za/wp-content/uploads/2012/02/TGA701_COKE_203-821-381 .pdf.

[19] P. Tanger, J. L. Field, C. E. Jahn, M. W. DeFoort, and J. E. Leach, "Biomass for thermochemical conversion: targets and challenges," Frontiers in Plant Science, vol. 4, article 218, 2013.

[20] ASTM Standards, ASTM D 5142-04: Standard Test Method for Proximate Analysis of the Analysis Sample of Coal and Coke by Instrumental Procedures, vol. 5, ASTM Standards, West Conshohocken, PA, USA, 2008.

[21] P. Elmer, 2400 Series II CHNS/O Elemental Analysis: Organic Elemental Analysis (2016), 2016, https://www.perkinelmer.com/ labsolutions//resources/docs/BRO_2400_SeriesII_CHNSO_Elemental_Analysis.pdf.

[22] C. Sheng and J. L. T. Azevedo, "Estimating the higher heating value of biomass fuels from basic analysis data," Biomass \& Bioenergy, vol. 28, no. 5, pp. 499-507, 2005.

[23] D. A. Skoog and J. J. Leary, Principles of Instrumental Analysis, Chapter 12, Harcourt Brace Jovanovich Philadelphia, Philadelphia, PA, USA, 1992.

[24] A. Anukam, S. Mamphweli, P. Reddy, and O. Okoh, "Characterization and the effect of lignocellulosic biomass value addition on gasification efficiency," Energy Exploration and Exploitation, pp. 1-16, 2016.

[25] B. M. Jenkins Jr. and T. Miles, "Combustion properties of biomass," in Fuel Processing Technology, T. L. Baxter, Ed., vol. 54, pp. 17-46, 1998.

[26] A. Abdolali, H. H. Ngo, W. Guo et al., "Characterization of a multi-metal binding biosorbent: chemical modification and desorption studies," Bioresource Technology, vol. 193, pp. 477487, 2015.

[27] E. Gustafsson, Characterization of Particulate Matter from Atmospheric Fluidized Bed Biomass Gasifiers [PhD. thesis], Linnaeus University, 2011.

[28] P. McKendry, "Energy production from biomass (part 3): gasification technologies," Bioresource Technology, vol. 83, no. 1, pp. 55-63, 2002.

[29] R. Fahmi, A. V. Bridgwater, I. Donnison, N. Yates, and J. M. Jones, "The effect of lignin and inorganic species in biomass on pyrolysis oil yields, quality and stability," Fuel, vol. 87, no. 7, pp. 1230-1240, 2008.

[30] J. S. Brar, K. Singh, J. Wang, and S. Kumar, "Co-gasification of coal biomass. A review," International Journal of Forestry Research, pp. 1-10, 2012.

[31] T. Chandrakant, "Biomass gasification-technology and utilisation," in Humanity Development Library (2002), 2012, http:// www.pssurvival.com.

[32] T. R. Miles, T. R. Miles Jr., L. L. Baxter, R. W. Bryers, B. M. Jenkins, and L. L. Oden, "Boiler deposits from firing biomass fuels," Biomass and Bioenergy, vol. 10, no. 2-3, pp. 125-138, 1996.

[33] D. Boström, N. Skoglund, A. Grimm et al., "Ash transformation chemistry during combustion of biomass," Energy and Fuels, vol. 26, no. 1, pp. 85-93, 2012.

[34] B.-M. Steenari, A. Lundberg, H. Pettersson, M. WilewskaBien, and D. Andersson, "Investigation of ash sintering during combustion of agricultural residues and the effect of additives," Energy and Fuels, vol. 23, no. 11, pp. 5655-5662, 2009.
[35] L. Wang, G. Skjevrak, J. E. Hustad, and M. G. Grønli, "Effects of sewage sludge and marble sludge addition on slag characteristics during wood waste pellets combustion," Energy and Fuels, vol. 25, no. 12, pp. 5775-5785, 2011.

[36] S. Xiong, J. Burvall, H. Örberg et al., "Slagging characteristics during combustion of corn stovers with and without kaolin and calcite," Energy and Fuels, vol. 22, no. 5, pp. 3465-3470, 2008.

[37] E. Lindström, M. Sandström, D. Boström, and M. Öhman, "Slagging characteristics during combustion of cereal grains rich in phosphorus," Energy and Fuels, vol. 21, no. 2, pp. 710717, 2007.

[38] D. Chen, Z. Zheng, K. Fu, Z. Zeng, J. Wang, and M. Lu, "Torrefaction of biomass stalk and its effect on the yield and quality of pyrolysis products," Fuel, vol. 159, article no. 9381, pp. 27-32, 2015.

[39] M. Wilk, A. Magdziarz, and I. Kalemba, "Characterisation of renewable fuels' torrefaction process with different instrumental techniques," Energy, vol. 87, pp. 259-269, 2015.

[40] G. S. Miguel, M. P. Domínguez, M. Hernández, and F. SanzPérez, "Characterization and potential applications of solid particles produced at a biomass gasification plant," Biomass and Bioenergy, vol. 47, pp. 134-144, 2012.

[41] S. Gaqa, S. Mamphweli, E. Meyer, and D. Katwire, "Synergistic evaluation of the biomass/coal blends for co-gasification purposes," International Journal of Energy And Environment, vol. 5, pp. 251-265, 2014.

[42] A. Anukam, S. Mamphweli, P. Reddy, O. Okoh, and E. Meyer, "An investigation into the impact of reaction temperature on various parameters during torrefaction of sugarcane bagasse relevant to gasification," Journal of Chemistry, vol. 2015, Article ID 235163, pp. 1-12, 2015. 

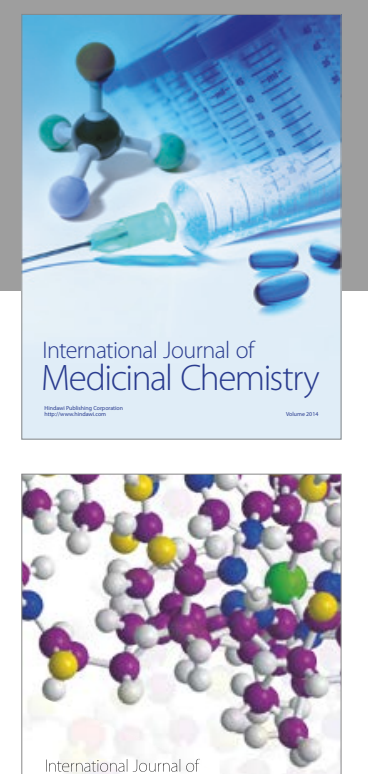

Carbohydrate Chemistry

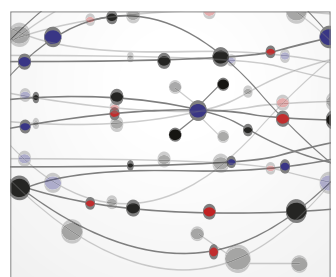

The Scientific World Journal
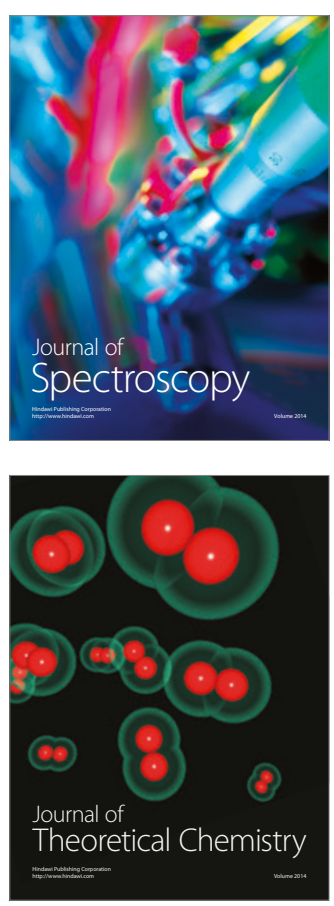
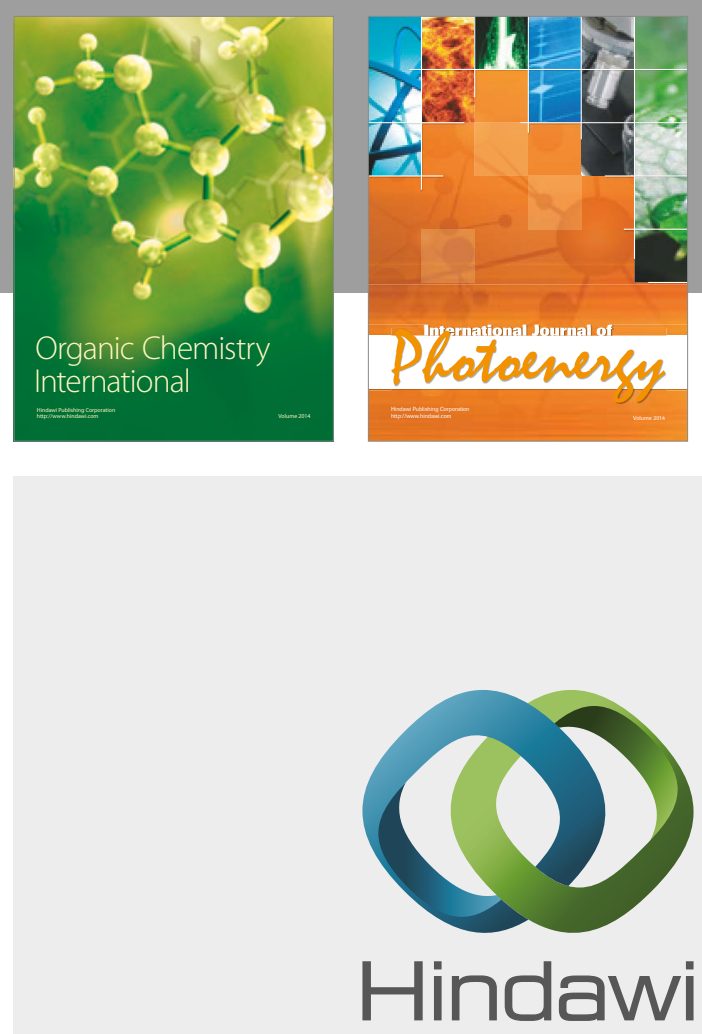

Submit your manuscripts at

https://www.hindawi.com

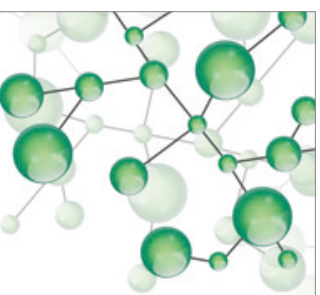

International Journal of

Inorganic Chemistry

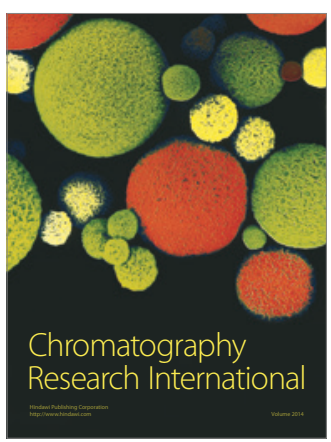

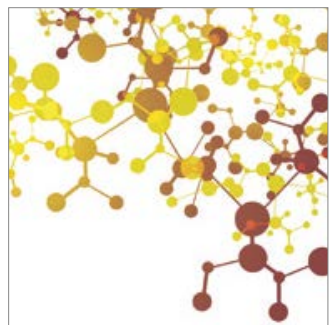

Applied Chemistry
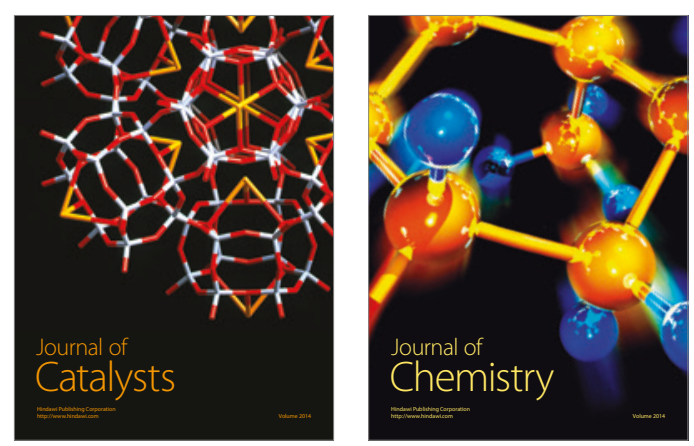
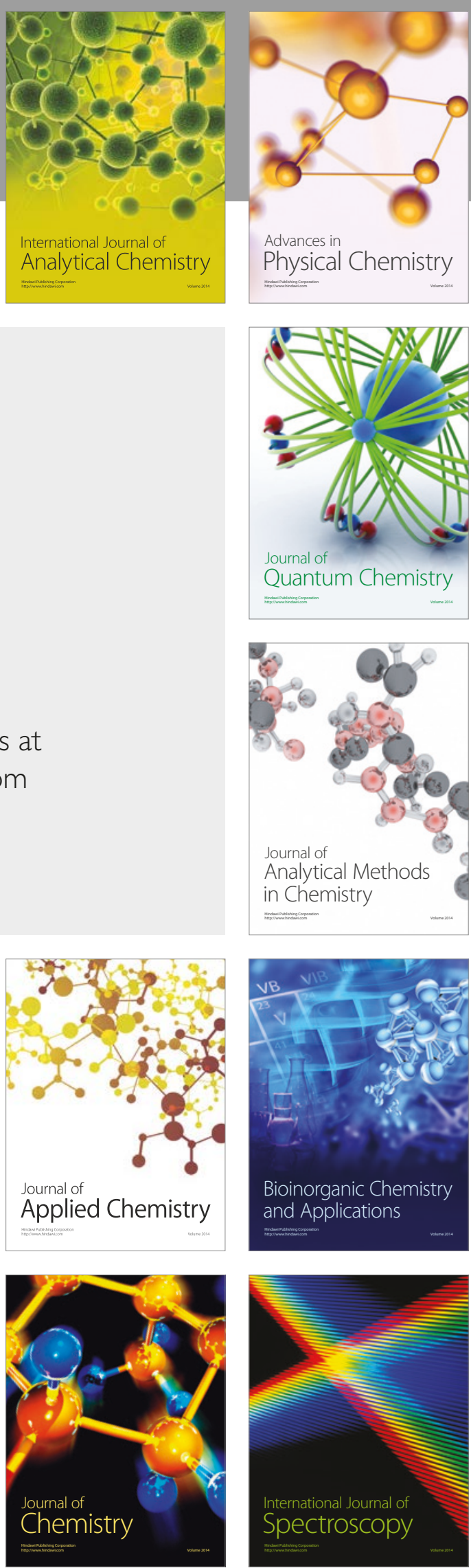